\title{
Commentary on Scientific Peer Review to Inform Regulatory Decision Making: Roles and Perspectives of Scientists
}

\author{
Gilbert S. Omenn*
}

This article from Patton and Olin at the Risk Science Institute of the International Life Sciences Institute provides timely and useful guidance for regulatory agency executives and research managers in response to the Office of Management and Budget/Office of Information and Regulatory Affairs (OMB/OIRA) bulletins on peer review for information quality. ${ }^{(1)}$ The segmentation into nine steps for effective peer review and the presentation of cautions and actions will be helpful to many, beginning with the overarching caution in the introduction: "Peer review is not a panacea. It can add credibility and enhance confidence in a scientific document, but it does not guarantee the accuracy or correctness of research findings or data analysis. Replication, additional testing, and confirmatory studies are the time-tested paths to factual accuracy."(2)

Scientific "opinion" is much less valuable, often leading to dueling experts (Fig. 1). Steps 3 (independence and expertise of peer reviewers), 5 (readiness of the document for review), 6 (clear charge to reviewers), and 8 (openness, disclosure, and balance) warrant special emphasis.

In this commentary, I will highlight the perspective of scientists asked to participate as peer reviewers. One of the most cogent commentaries on the role of scientists is a speech called "The Perils of Wizardry" by David L. Bazelon, long-time Chief Judge of the Federal First Circuit Court of Appeals, which heard many of the landmark cases arising from regulatory agencies, from the Nuclear Regulatory Commission to the Environmental Protection Agency. Judge Bazelon's premise was that technical experts (both in-

\footnotetext{
* Internal Medicine, Human Genetics and Public Health, University of Michigan, A510 MSRB I, Ann Arbor, MI 48109-0656; tel: 734-763-7583; fax: 734-647-8148; gomenn@umich.edu.
}

side and outside the agency) lack the charge and have no special expertise to address the ultimate policy decision. Instead, scientists should delineate the specific elements of the characterization of risk, focus on the nature and quality of the relevant evidence for each element, and build the record. He observed that scientists often will agree on what is definitely known, what has been studied but has uncertain findings, and what is not yet feasible to study, even though they may be employed by or consulting for entities with opposite views on what needs to be done. Since regulatory issues tend to recur, a credible, explicit record will facilitate analyses the next time around. ${ }^{(3)}$

Among many other mandated topics, the Presidential/Congressional Commission on Risk Assessment and Risk Management, which I had the privilege to chair during 1994-1997, addressed various aspects of peer review. ${ }^{(4)}$ The Commission took the following positions:

1. Peer reviewers can enhance the technical quality and the credibility of agency reports and decisions.

2. Peer reviewers should evaluate the quality of various types of analyses: toxicologic, epidemiologic, exposure, engineering, economic, behavioral, and modeling.

3. Peer reviewers must address the credibility of assumptions and interpretations.

4. Peer review should be an open process, informed by stakeholders (via separate processes of participation and public comment), and placed in broad context.

5. The extent of peer review should be commensurate with the importance of scientific or economic issues and regulatory impact of the decision. 


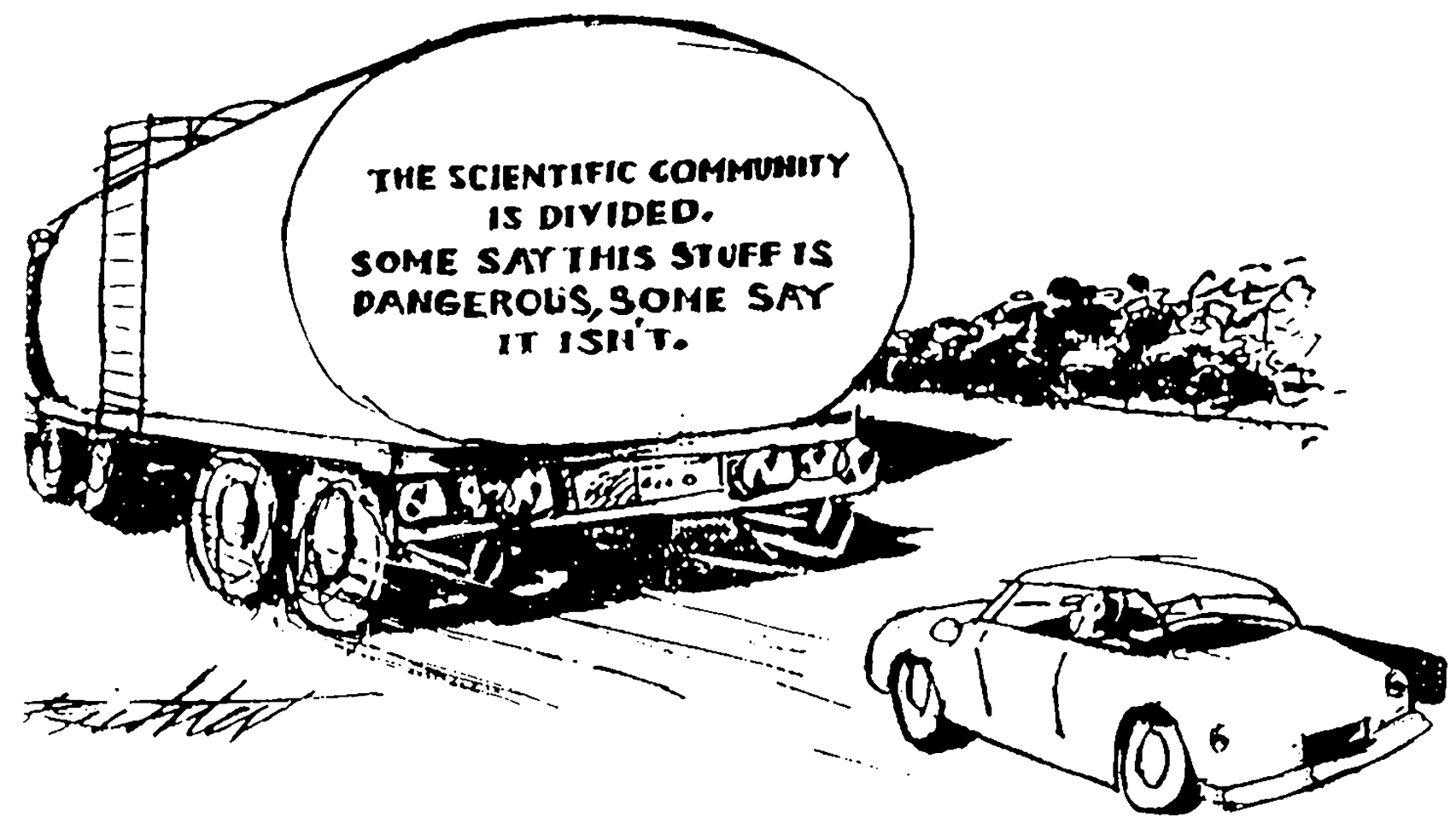

Fig. 1. Cartoon showing how confusing disclosure can be that apparently qualified scientists issue opposing views on whether a particular substance or exposure is hazardous (and what should be done about the risk).

When asked to serve as a peer reviewer, the individual scientist may want to know the length and complexity of the document, the likely time required, the nature of the key scientific controversies or issues about methods, assumptions, and findings (partly to anticipate any "bias" to be disclosed), whether the document is limited to published literature or includes unpublished "grey" literature, who else is on the panel, and what domain each reviewer is counted on to cover in depth. Increasingly, environmental groups and industry associations are challenging the choice of panelists not just at regulatory agencies but also at the National Research Council. Peer reviewers must be willing to perform a serious and thoughtful assessment, yet be timely while meeting other obligations. A carefully balanced roster of reviewers may come unraveled when some decline to participate, and when reviews are perfunctory ("looks fine") or argumentative or too narrowly focused. These complications put a burden on the requesting agency to deal with uneven or unbalanced evaluations.

The proposed and even the substantially modified final OMB Bulletins ${ }^{(1)}$ heightened the sensitivity of scientists to the criteria for conflict of financial interest, proposing to disqualify even holders of com- petitive research grants; for bias, requiring minimal familiarity with the topic and embedded issues; and for experience, discouraging repeat service, which may lead an invited scientist to wait for a more interesting request or a better match to his or her expertise. Scientists may respond variably to the proposed disclosure of one's name and funding sources; some may consider it a well-earned "credit," while others may fear it invites unwarranted attacks from those with a lot at stake, ${ }^{(5)}$ especially from those demanding "corrections" by the responsible agency, as encouraged by the Bulletin. Nevertheless, as with requests from journals, most scientists do, indeed, agree to make a good effort when asked to participate in peer reviews.

As I recommended at a National Research Council Workshop in 2003, ${ }^{(6)}$ agencies should (1) provide invited peer reviewers adequate context and clear charges; (2) improve the management of their peerreview processes along the lines of the OMB Bulletin and Patton and Olin; and (3) use both standing advisory committees with rotating, balanced membership familiar with the agenda (like the Clean Air Act Scientific Advisory Committee) and National Research Council/Institute of Medicine-type ad hoc peer-review panels. OMB/OIRA, in concert 
with the Office of Science \& Technology Policy, should oversee rather than micromanage the peer-review processes of agencies and interagency committees. Finally, OIRA should respect the peer-review effort requested of the scientific community with a sufficient threshold for initiating full-scale peer reviews.

\section{REFERENCES}

1. Office of Management and Budget, Office of Information and Regulatory Affairs. (2003). Information quality bulletin for peer review. Federal Register, September 15, 2003, and (Revised) December 15, 2004. Available at http:// www.whitehouse.gov/omb/inforeg/peer2004/peer_bulletin.

2. Patton, D. E., \& Olin, S. S. (2006). Scientific peer review to inform regulatory decision making: Leadership responsibilities and cautions. Risk Analysis, 26(1).

3. Bazelon, D. L. (1979). The Perils of Wizardry. Unpublished lecture, University of Southern California.

4. Presidential/Congressional Commission on Risk Assessment and Risk Management. (1997). A Framework for Environmental Health Risk Management (Vol. 1), Assessment and Risk Management in Regulatory Decision-Making (Vol. 2). Washington, DC: U.S. Government Printing Office. Available at http://www. riskworld.com

5. Deyo, R. A., Psaty, B. M., Simon, G., Wagner, E. H., \& Omenn, G. S. (1997). The messenger under attack-Intimidation of researchers by special-interest groups. New England Journal of Medicine, 336, 1176-1180.

6. Omenn, G. S. (2003). Perspectives of Peer Reviewers on OMB Bulletin on Peer Review Standards for Regulatory Decisions and Technical Information. Washington, DC: National Research Council Workshop. 